\section{BORROSIDADES PATOLÓGICAS}

\author{
Luis Ferrer i Balsebre \\ Profesor Asociado. Departamento de medicina \\ Universidad de A Coruña. Médico Psiquiatra Jefe del Servicio \\ de Salud Mental del Complejo Hospitalario Universitario de \\ Santiago de Compostela \\ Luis.Ferrer.Balsebre@sergas.es
}

Cómo citar este artículo/ Citation: Ferrer i Balsebre, L. (2013). "Borrosidades patológicas". Arbor, 189 (762): a055. doi: http://dx.doi.org/10.3989/arbor.2013.762n4006

Recibido: 13 julio 2012. Aceptado: 6 junio 2013.

RESUMEN: En este artículo se analizan los cambios sociales derivados de la llamada Posmodernidad y su relación con las patologías psíquicas emergentes. El declive de los valores, el cambio en las categorías de tiempo y espacio, los cambios en los sentimientos de pudor y vergüenza, la pérdida de la función de autoridad junto con la adultización del niño y la infantilización del adulto, el fenómeno del consumo, el riesgo como factor de vida y la primacía de la emoción, los cambios en la estructura familiar y la función social de los hijos, son algunos de los puntos analizados. Dichos factores determinan la aparición de nuevas patologías así como cambios de prevalencia de diversos cuadros clínicos.

PALABRAS CLAVE: Posmodernidad; valores; patologías emergentes.

\section{PATHOLOGIC FUZZINESS}

Copyright: (c) 2013 CSIC. Este es un artículo de acceso abierto distribuido bajo los términos de la licencia Creative Commons Attribution-Non Commercial (by-nc) Spain 3.0.

ABSTRACT: This article explores the social changes arising from what has come to be termed Postmodernity and their connections to emerging mental illnesses. The decline in values, the change in the categories of time and space, the changes in the feelings of modesty and shame, the loss of the role of authority together with the adultisation of children and the infantilisation of adults, the phenomenon of consumption, risk as a factor of life and the primacy of the emotion, the changes in the family structure and the social function of the children, are some of the points subject to the analysis. Such factors determine the emergence of new pathologies as well as changes of prevalence in diverse clinical profiles.

KEYWORDS: Postmodernity; values; emergent pathologies. 


\section{INTRODUCCIÓN: BORROSIDAD Y POSTMODERNIDAD}

La borrosidad que la época posmoderna ha generado en muchos aspectos sociales ha tenido su efecto en las maneras de sufrir, en la aparición de nuevas patologías emergentes y en la desaparición de otras habituales.

Ya Hipócrates en su obra De los aires, las aguas y los lugares, alertaba de la importancia de conocer los entornos del enfermar y del sanar. $Y$ de esta importancia da cuenta el hecho siguiente, referido a nuestro contexto histórico. Hablaba yo hace poco con unos colegas recién jubilados que comentaban estas opiniones y me confirmaban que la patología que ellos habían tenido que atender era uniforme, de fácil taxonomía y filiación pero que, a partir de los ochenta, el perfil de los pacientes comenzó a cambiar hasta el punto de resultar en ocasiones inclasificable. Algunos autores, como Guillermo Rendueles, habla de la proliferación de OPNIS, esto es, de objetos psiquiátricos no identificados.

Así que junto con "el fin de la historia" como ha identificado Fukuyama al momento actual, parece que asistimos al declive de aquellas entidades expuestas en los envejecidos tratados y manuales de psicopatología, y vemos cada vez más entidades borrosas, nuevas terminologías y nuevos tipos de pacientes. Tal pareciera que la sociedad y los sujetos se han transformando mucho más rápidamente que nuestra capacidad para pensarlos, y que nuestras teorías han llegado tarde a la transformación apresurándose, también ellas, a cambiar, adaptándose, adecuándose a la misma fragmentación, desarrollando sistemas clasificatorios como el DSM IV (Asociación Americana de Psiquiatría, 2002), obligadas a clasificar y reclasificar incesantemente la realidad psicopatológica; olvidándose de que el mapa no es el territorio y que las clasificaciones ordenan, pero a veces nada dicen de lo ordenado.

Los siguientes son algunos datos epidemiológicos relevantes ${ }^{1}$ :

. $15 \%$ de prevalencia de depresión mayor y $5 \%$ para distimias.

- $10 \%$ de la población sufre o ha sufrido de ansiedad generalizada.

- 7\% de los jóvenes tendrán un intento de suicidio antes de los 25 años.

- 15\% de la población presenta trastornos de personalidad (10 veces más que la esquizofrenia y los trastornos afectivos y casi igual que los cuadros de angustia/ansiedad).
- Los trastornos de la alimentación aumentan de un 0,3\% en 1985 al $2 \%$ en el 2000.

- El consumo de antidepresivos aumenta un $270 \%$ entre 1985 y $2000^{2}$.

- Los fármacos ansiolíticos son los más consumidos por la población ${ }^{3}$.

- El 43\% de los jóvenes entre 14 y 18 años consumen alcohol el fin de semana.

- El promedio de edad en el inicio del consumo es de 13,5 años.

- La cantidad de jóvenes que consumen alcohol aumentó un $20 \%$ en los últimos diez años.

- España ocupa el segundo lugar del mundo en tasa de alcoholismo juvenil.

- El Complejo Hospitalario Universitario de A Coruña atendió 207 comas etílicos de jóvenes entre 13 y 23 años en el 2005.

- En Galicia 100 jóvenes menores de 16 años cumplen medidas judiciales por agresión a los padres. (Síndrome del Emperador).

- El $10 \%$ entre 3 y 18 años incurren en violencia Filio-parental.

. El 29\% en hogares monoparentales maternos ${ }^{4}$.

- El 40\% de los jóvenes de 24 años no entienden el Editorial de un periódico ${ }^{5}$.

- El 30\% de los estudiantes NO acaba secundaria, y el $50 \%$ abandona la Universidad ${ }^{6}$.

Trataré ahora de ensayar una explicación de estos datos desde el nivel de realidad sociocultural, siguiendo el modelo de etiopatogenia del síntoma psíquico desarrollado por el Dr. Santiago Lamas Crego (Lamas Crego, 1988) en el que se entiende la enfermedad mental desde la complejidad que abarcan los diferentes niveles de realidad (biológico, intrapsíquico, relacional familiar, sociocultural...) desde los que puede generarse el sufrimiento psíquico y que interactúan de forma recursiva entre sí.

La variación en la prevalencia de las diferentes patologías psiquiátricas constatada epidemiológicamente en los últimos cuarenta años y su comprensión desde los cambios socioculturales que supuso la época posmoderna, se propone desde la selección de los que consideramos los rasgos que más claramente evidencian dicha relación. Cabría desarrollar muchos otros, pero en aras de la brevedad nos ceñiremos a los que a nuestro juicio ejemplifican mejor 
su influencia en la práctica clínica diaria de la psiquiatría y la psicología clínica.

La sociedad contemporánea constituye un ambiente inestable y exigente para la constitución de la subjetividad. Enfrentamos el peligro de destrucciones mucho más extensas y "globales" que en el pasado: ya sea de carácter bélico, ecológico o financiero. El mundo, gracias a la informática, se ha empequeñecido y somos más conscientes de cómo los acontecimientos próximos dependen de los ya-no tan lejanos.

La literatura actual sobre los efectos de estas modificaciones sociales es enorme, pero la mayoría de los estudios coincide en que todo se mueve, nada permanece, no hay futuro ni pasado que sirvan como referentes. El tiempo y el espacio se han modificado, la vergüenza y la culpa han trastocado su lugar tradicional, y cada día hemos de vivir decidiendo cómo queremos vivir al día siguiente. ¿Cómo construirse en todo ello? ¿Cómo adaptarse a este vértigo? La exigencia resulta desmesurada. La angustia deviene entonces un estado más o menos permanente.

Las transformaciones sociales que vamos a ver a continuación nos llevan a la constitución de un "yo posmoderno" que Gergen (Gergen, 1992) considera como el producto de las tecnologías y la saturación social. Los mails, móviles, televisión, aviación, etc. nos conectan con miles de personas en miles de lugares, recibiendo información inmediata de todo el mundo al momento. Inmerso en múltiples relaciones cambiantes, para este yo actual, todo se tambalea. Lo duradero se vuelve efímero; lo estable inestable. Las pautas de relación se vuelven plurales, múltiples y muchas veces virtuales desarrollándose un nuevo entorno de relación a través de la red de internet.

Este yo posmoderno, flexible, adaptable y polimorfo, tiene también algunos inconvenientes. En concreto, es frágil, quebradizo, fragmentado y narcisista. Con la saturación social nos convertimos en depositarios de múltiples personalidades ocultas, de varias voces interiores. Nuestro yo se convierte en una pauta de relaciones.

La saturación se traduce socialmente en superabundancia vacía, - como señala Lipovetsky (Lipovetsky, 1986) - . Se trata de superabundancia de información, de servicios y de bienes de consumo. Curiosamente, esta disponibilidad infinita conduce a un estado característico de nuestra cultura posmoderna: el aburrimiento y la desilusión. Pero no se trata del aburrimiento romántico y melancólico, sino de un aburrimiento integral al que se llega por el hecho de poder hacerlo todo; por el hecho de haber recorrido en poco tiempo todo el espacio que ocupa un proyecto voluntario. Podríamos decir que la de hoy es una acción sin objetivo concreto porque los objetivos básicos están cubiertos y los superfluos son tan fáciles como cambiantes.

Las peores expresiones conductuales del aburrimiento por saturación las encontramos en dos fenómenos nuevos: la violencia desalmada de adolescentes que manifiestan llevarla a cabo "porque se aburren", y el aumento de adultos saturados de estímulos sexuales que devienen consumidores de pornografía infantil a través de Internet. El perfil de este cibernauta que ya no sabe qué consumir para estimularse, no tiene nada que ver con la parafilia de siempre descrita en nuestros tratados de psicopatología.

La pérdida de puntos sólidos de referencia, así como la desaparición de los viejos ritos y de hábitos duraderos crea una intranquilidad difícil de sobrellevar, de aquí que muchos consideren a esta tensión o "stress", junto con la depresión, como la principal problemática de salud de nuestro tiempo. Otros señalan al aumento de la violencia intrafamiliar y social, las adicciones y los trastornos adaptativos como las consecuencias de la dificultad de adaptarse a todos estos cambios.

Hoy estamos obligados a adaptarnos de forma constante a las nuevas tecnologías, a nuevas formas de ocio, de vida, de familia, de moneda, de normas y hasta de estructura social, hecho insólito en la humanidad que tardaba siglos en cambiar una estructura.

La revolución del '68 supuso el paso de una sociedad postfigurativa, en la que los hijos aprendían los modos y maneras de vivir de los adultos, a otra configurativa en la que los hermanos pequeños aprendían esos modos de sus hermanos mayores. De esta estructura se pasó, con la caída del muro de Berlín, a una estructura prefigurativa en la que son los adultos los que adoptan los modos y maneras de los jóvenes. Es el boom de los yuppies, los jasps, los liftings, lo ligtht, la cirugía estética, la dieta; en definitiva, el cuerpo y las maneras jóvenes como valor social predominante.

En el campo de la ciencia dura (hard science) se ha puesto también de manifiesto esta concepción del pensamiento. La inestabilidad que caracteriza el mundo de hoy abarca también la materia física. El universo mecanicista de Newton ha dejado paso a un universo mucho más inestable. Eso ponen de manifiesto los trabajos sobre sistemas en desequilibrio y termodinámicos de I. Prigogine. Él viene a decir que cuando un sistema pierde su equilibrio se comporta de forma 
extraña y de ningún modo sigue un comportamiento mecanicista, de tal manera que un pequeño estímulo puede producir grandes consecuencias y viceversa. El azar entra en circulación. No hay sistemas cerrados, sino que estos interactúan constantemente; cuando su inestabilidad es mayor es cuando más sensibles se vuelven a las fuerzas interactivas y al azar, de manera que los resultados pueden ser impredecibles. Un ejemplo claro de esto lo constituye la polémica sobre una simple caricatura de Mahoma ${ }^{7}$, que fue capaz de crear un efecto de consecuencias planetarias.

Partiendo de este encuadre general, intentaré señalar algunos de los cambios que a mi juicio nos han influido más.

El término Posmodernidad es ambiguo y borroso. En cualquier caso, no se puede hablar de postmodernidad sin definir antes en qué consiste su antecesor, la Modernidad.

La Modernidad es un conjunto de formas simbólicas que se encarnan en Europa a partir del Renacimiento y que comienzan a debilitarse con la muerte de Nietzsche en 1900. La Modernidad abarca desde el siglo XV hasta finales del XIX. En ella destacan dos periodos especiales: el Renacimiento, en el que se revive la tradición grecorromana poniendo al Hombre como valor fundamental, y la llustración - seguida de la Revolución Francesa, la Revolución industrial y el Positivismo- con el valor de la Razón por bandera. Es la época de las grandes esperanzas de futuro para la humanidad, de los grandes ideales de paz y progreso.

Poco a poco este espíritu va a ir alterándose. Europa va paulatinamente a ir desencantándose de sus ideales: triunfan el capitalismo, el imperialismo, la globalización, los antagonismos (nazismo y comunismo), la exterminación de masas, dos guerras mundiales, el terrorismo, la corrupción política, el consumismo, la producción, el ocio, la tecnología... El hombre deja de creer en los ideales de progreso, la felicidad y su redención, propios de la Modernidad, mirando con escepticismo la fe en la razón. Europa abandona así sus convicciones y transita hacia la Posmodernidad.

La verdad acaba siendo el resultado de una interpretación de interpretaciones, perdiendo consistencia. La razón se disuelve, la opinión pública sustituye a la voluntad general de Rousseau. En lugar del pueblo, encontramos ahora a las masas; en lugar del ciudadano aparece el consumidor y el usuario.

La Posmodernidad se diferencia de la Modernidad en que no acepta la existencia de realidad alguna que se presente como absoluta, trátese de Dios, del Hombre, de la Ideología, o de la Razón. En lo postmoderno se mueven dioses, ideologías, razones intercambiables.

Si tuviéramos que definir los rasgos fundamentales de este ambiente posmoderno destacaríamos los siguientes:

\section{EL DECLIVE DE LOS VALORES TRADICIONALES}

Hasta hace poco sustentaban nuestra civilización: el esfuerzo, el valor del trabajo, la autoridad, respeto patriarcal y su sucesiva atomización en múltiples valores, a veces contradictorios entre sí.

Así como el hombre moderno vivía según un discurso racional sobre el mundo y en términos de una verdad única y absoluta; una vez perdida su confianza en cualquier tipo de metanarración, de gran relato, vive en medio de una pluralidad de narraciones relativas o de verdades proclamadas sin certeza en los diversos contextos del saber.

De esta manera, no solo carece de una única verdad, sino que la idea misma de verdad ha perdido para él todo sentido. Es decir, ha entrado en crisis no solo aquella razón que se había arrogado el derecho y la tarea de dar fundamento a todos los valores, sino la razón como tal, con todas sus capacidades. A partir de este momento, el hombre posmoderno tendrá que buscar su propia mística, su propia razón y su propia verdad.

Esto puede ser alentador en algunos aspectos, como la libertad y evolución civilizada del hombre, pero en otros resulta más complejo. La posibilidad de una elección individual de valores ante la ausencia de valores socialmente predefinidos implica una elección narcisista, individual, que en ocasiones choca frontalmente con las del otro, complejizando las relaciones sociales y determinando la proliferación (con muchos más casos de los que nunca hemos visto antes) de individuos "curiosos" como señala Millon (1999); "anormales" como definía Schneider, y con trastorno de personalidad como diagnosticamos todos.

El hombre posmoderno está obligado a la elección permanente sin otra referencia que uno mismo y la lógica predominante de la novedad y el cambio como valores en uso. Podría decirse que el gusto por lo nuevo ha desembocado en el gusto por lo efímero, como señala Lipovetsky.

Debemos elegir $-\mathrm{y}$ renunciar - en todos los aspectos: desde el canal de televisión al culto religioso; 
desde el tipo de familia al estilo de alimentación; desde el modelo de teléfono móvil al tipo de sexualidad; desde el estilo de ropa (se acabaron las tendencias) a los estudios de posgrado. Y todo ello, insisto, de forma rápida y sin referente ni absolutos en los que poder orientarse. Nuestra vida estaría, así, sometida a la permanente angustia del acierto en la elección y a la frustración por la renuncia o la incapacidad de elegir.

No es de extrañar, entonces, que los cuadros de angustia/ansiedad se hayan multiplicado por cuatro en los últimos diez años.

\section{EL CAMBIO DE LAS CATEGORÍAS DE TIEMPO Y ESPACIO}

Dichas categorías están mediadas sobre todo por la tecnología informática y por las nuevas comunicaciones. Estas hacen del tiempo algo inmediato y del espacio algo soslayable sin dificultad. Dichos cambios implican la anulación de la función psicológica de la espera, que es crucial para introducir un tiempo de comprensión entre el instante del deseo y el de su conclusión. Todo esto lleva a una disminución -en nuestra sociedad- de la tolerancia a la frustración generalizada, antesala de la violencia y de las conductas en "acting-out" o corto-circuito, que constituye un rasgo nuclear en la mayoría de los trastornos de conducta y personalidad.

La vivencia actual del tiempo y del espacio es pues más transversal que longitudinal: se vive más que nunca en el "aquí y ahora". El tiempo psíquico deviene veloz y fugaz, la conducta y la comunicación instantánea y dispersa.

No es extraño ver a gente en el cine comentando algo con el de al lado y al mismo tiempo enviando mensajes. Estos rasgos de aceleración, fugacidad y dispersión de la atención son típicos de los cuadros hipomaníacos. La sociedad posmoderna es maníaca y, por tanto, propensa al repunte de todos los trastornos de tipo afectivo que se han multiplicado por diez en todas sus variantes clínicas, así como a los llamados trastornos de hiperactividad o déficit de atención.

Otro tanto ocurre con los ritmos biológicos, así el del sueño/vigilia o el ritmo hambre/saciedad.

Muchos ciudadanos y ciudadanas se ven "obligados" a engañar el hambre en aras de la prisa o de la estética con frugales tentempiés o galletitas energéticas. Aparte de las alteraciones biológicas que esto pueda suponer, aparece la alteración psicológica de los trastornos de la alimentación, hoy día tan de moda, tan emergentes. Tocar este reloj, alterar el rit- mo, puede llevar a la indiferencia diabólica frente al comer en forma de anorexia, o al asalto nocturno a la nevera de un ejército de bulímicos acosados por su propia trasgresión al ritmo.

El rito de la comensalidad cuando se vuelve borroso o se transgrede, se transforma en el ritual del comensal.

El ritmo biológico del sueño/vigilia también ha sufrido sus alteraciones. Hoy se puede hacer de todo, a todas horas. Esto está bien, pero le ha roto los ritmos y los nervios a mucha gente. El insomnio es también una de las patologías en auge. La alteración del sueño se corrige con píldoras para dormir, y la resaca de las mismas con píldoras para espabilarse o litros de café. En suma, estamos poniendo el reloj biológico en manual cuando es, naturalmente, automático.

\section{EL SENTIMIENTO MORAL DE LA VERGÜENZA Y EL PUDOR}

De ser un signo de humanidad, estos sentimientos han dado lugar a una desinhibición (de nuevo otro rasgo hipomaníaco) que elude cualquier tipo de represión, haciendo de lo otrora motivo de culpa, un elemento de exhibición y espectáculo, como podemos comprobar a diario en los reality shows. La culpa y la vergüenza por algo ya no son contenidos habituales de represión en el inconsciente; por el contrario, parece que son sustituidos por la angustia por nada como síntoma posmoderno primordial.

La solución religiosa que proponía una felicidad más allá de este mundo, cargando las tintas en la culpa y la vergüenza como mecanismos simbólicos de autocontrol, ha sido reprimida en la Posmodernidad, como lo fuera la sexualidad en la época victoriana -tesis defendida por el pensador británico John Gray (Gray, 2002)-

Pero como Freud ya explicó muy claramente, lo reprimido siempre regresa y lo hace bajo forma de síntomas. Síntomas que aparecen como una proliferación de nuevas "religiones" a la carta de las cuales la ciencia es la más representativa. Igual que aquellas, esta promete la salvación, solo que no lo hace bajo la forma de una resurrección gozosa, sino de una especie de inmortalidad y seguridad terrena que para nada parece confirmarse.

El fin de la historia que preconizaba Fukuyama, haciendo referencia a que la tecnología y la globalización supondrían el fin de las revueltas mundiales, o las ideas de Keynes acerca de la superación de la amenaza de escasez de recursos una vez desarrollada la 
era industrial, se están demostrando completamente equivocadas.

Después de la deflagración histórica que supusieron las luchas políticas del siglo XIX o las ideológicas del siglo $X X$, nos vemos abocados de nuevo a viejas confrontaciones que creíamos superadas: el conflicto por los recursos (la guerra de Irak es buen ejemplo de ello) y la religión. Ambas suponen causas típicamente medievales.

Por otra parte, nuestro bienestar posmoderno choca frontalmente con otras civilizaciones que, no disfrutando del mismo, mantienen la religión como valor e ideal que aglutina voluntades y arremete contra el bienestar del otro lado. Europa es el $17 \%$ de la población mundial, un continente viejo y rico que debe convivir rodeado de gentes pobres y jóvenes. Terrorismo e inmigración son dos grandes amenazas del bienestar posmoderno que tendrán sus consecuencias psíquicas, como se expondrá más adelante.

\section{DE LA JERARQUÍA A LA HORIZONTALIDAD DE LOS VALORES}

La jerarquía de los valores personales, sociales y familiares ha dado paso a una horizontalidad donde los límites devienen borrosos, siendo cada vez más difícil ocupar cualquier lugar simbólico de autoridad, sea familiar, laboral o social.

La sociedad tecnológica ha abierto, entre otras muchas cosas, la posibilidad del acceso permanente de los niños y adolescentes a los mismos circuitos de ocio e información que los adultos. Ya no existen lugares, imágenes o informaciones restringidas al adulto de forma exclusiva.

Ello ha derivado en una progresiva "adultización" del niño, que puede acceder a los mismos contenidos que el adulto. El universo de lo que hasta ahora entendíamos como la edad de la inocencia, se desmorona. Podríamos hablar sin demasiada exageración de una especie de "muerte de la infancia". No es de extrañar que los niños y los adolescentes estén protagonizando sucesos violentos hasta hace poco insólitos a esas edades.

Paralelamente a esta adultización del niño, se está produciendo una progresiva "infantilización" del adulto. Es decir, está ocurriendo una especie de difuminación de los límites entre ambos mundos.

La infancia y la adolescencia postmoderna están sufriendo un retroceso al periodo comprendido entre los siglos XIII y XV, en el que el niño era contemplado como "un adulto pequeñito", capaz de razonar, juzgar o decidir como un adulto.

El discurso creado en torno al niño se ha inflado de tal modo que se reivindica su "derecho al goce ilimitado". Cualquier acto de frustración del deseo del niño es vivido con culpa por unos padres borrosos (generalmente culpabilizados por no disponer de tiempo suficiente para estar con el niño), que cada vez se muestran más incapaces de administrar ese deseo.

Se difuminan así las referencias claras de lo que debe ser un padre que asuma la función simbólica de autoridad, es decir, del personaje nutriente que cuida, protege y premia; pero que también castiga, frustra, administra y castra el deseo cuando es necesario. Esta falla primaria para el niño, necesaria para la construcción de una conciencia moral y de capacidad de autocontrol, es la que más tarde conducirá a un cuestionamiento generalizado de toda Autoridad (con mayúsculas), y de la Ley (también con mayúsculas). Las conductas "retadoras", violentas e impulsivas, son ya hoy un latido emergente en nuestra clínica y en la sociedad, siendo solo un ejemplo el del desafío de los macrobotellones.

La autoridad pierde su referente en el adulto, produciéndose la infantilización del mismo que se expresa por un desvanecimiento de las diferencias entre ambos (en el vestir, en el comer, en el hablar, en los horarios, en el ocio...). Nos encontramos frente a unos adultos que son una especie de "jovencitos perpetuos" generalizados.

La diferencia fundamental entre un niño y un adulto está en que el adulto lo es porque se hace responsable de su deseo y de sus actos y asume las consecuencias.

Cada vez hay menos gente adulta porque cada vez el sujeto de la Posmodernidad actúa más, pero no se responsabiliza de sus actos. Cada vez se vive más bajo la premisa del "dejadme en paz y ocuparos de mis asuntos".

Se puede así fumar y pedir responsabilidades por las consecuencias a la tabacalera; envenenarse con todo tipo de drogas y "exigir" su cura y control a los poderes públicos. Curiosa posición esta en que las conductas voluntarias reclaman un control externo a uno mismo, al contrario que los síntomas. Ningún diabético exige que se cierren las pastelerías. A este adulto posmoderno se le disculpa todo. Se le disculpa porque, como a los niños, no se le considera responsable.

La disculpa viene generalmente por la vía de la conversión de la responsabilidad en una enfermedad. La 
diferencia entre un síntoma y una conducta está en que los síntomas son, por definición, involuntarios. Las conductas no.

Se reformulan las conductas como síntomas y el sujeto queda exculpado: de ser un jugador, un mujeriego o un chulo pasa a ser un ludópata, un adicto al sexo o a la violencia de género. La sociedad así lo juzga: "no puede ser normal, tiene que estar enfermo". Y por esta razón, cada vez hay más psicópatas que se ponen la máscara de sufridor con el fin de perpetuar sus conductas, con la absoluta buena conciencia de ser unos canallas inocentes, como señala Pascal Brukner (Bruckner,1996).

El siguiente paso es arrojar estos sujetos a las profesiones de ayuda que "entienden" de enfermedades y exigir su cura. Y como consecuencia de este paso, el siguiente lo constituye nuestra impotencia terapéutica frente a quien no reconoce responsabilidad alguna en su sufrir.

Por su parte, el niño posmoderno, adultizado, pierde el referente de lo que es un padre (un adulto) porque este también está borroso. ¿Quién sostiene entonces la autoridad para poner y señalar los límites? ¿Quién encarna el modelo adulto? ¿Quién asume la responsabilidad?

La palpitante polémica sobre la violencia en las aulas y las quejas desesperadas de la gente de la enseñanza es una consecuencia de lo dicho. Tampoco el aula es un referente de autoridad. Los derechos ilimitados del alumno impiden la interposición de un límite. El alumno no será cuestionado mientras se apela a sus derechos o a que "tiene problemas" (de nuevo un síntoma).

Los docentes se quejan, afligidos, de algo que ya pronosticara Lacan en torno a la segregación: los estados modernos lanzados a una política de supresión de las diferencias, reciben en lo real la respuesta: son los propios sujetos los que se segregan en función de su deseo particular.

Así, tenidas por progresistas unas medidas no segregativas se llega a no eliminar a los repetidores y a colocar en una misma aula a alumnos extremadamente diferentes; grupos de alumnos a los que interesa poco el saber se convierten así en los reyes de las aulas y, a través de la violencia, dictan la ley de su deseo particular. Es la reintroducción perversa de la necesaria diferencia que la estupidez homogeneizadora pretende borrar.

Al adulto postmoderno que concede todos los derechos y responsabilidades al joven de la Postmoder- nidad, le responde este tomándose el único derecho que le importa profundamente: el de su satisfacción; un goce que se va a manifestar en un auge de la violencia en los centros de enseñanza.

Allí donde hay violencia hay un déficit de palabras. Es verdad. La cultura posmoderna es una cultura de la imagen; allí donde había palabras, ahora hay imágenes.

Pero se predica el "diálogo", del mismo modo que el niño desarrolla actividades en solitario con el microondas, la video niñera, las videoconsolas, y demás actividades mudas y solitarias. Están carentes de adultos que actúen como "terroristas semióticos", según dice Umberto Eco; adultos que filtren, interpreten y maticen la realidad que observan los niños, que introduzcan un cierto "orden" en todo ese caos informativo.

Al desaparecer la conciencia del límite, aparece el consumo y el placer desordenado y, en definitiva, el culto a las apariencias como forma posible de realidad. Nos encontramos con el culto al cuerpo y a la imagen, el culto al envoltorio (el valor del regalo se mide por el envoltorio); el culto a la información (pero entendida como archivo, no como memoria, otra palabra clave que ha perdido su significado).

\section{EL CONSUMO}

Es en esta época posmoderna en la que asistimos al fenómeno del consumo generalizado. El hombre posmoderno consume, luego existe. La lógica implantada del consumo nos ha hecho dejar de desear lo que necesitamos, para pasar a necesitar lo que deseamos, y todo es una permanente propuesta de oferta y seducción:

- Consumo de bienes materiales como símbolo de rango social. El sujeto pasa de ser la persona que compra a ser lo que compra; pasa del "yo soy el que compra" al "yo soy lo que compro".

- Consumo médico: presenciamos la paradoja de sujetos con una resistencia frontal a la medicina oficial que recurren a todo tipo de remedios alternativos, junto a la forma sutil de subversión que supone una generalización del consumo excesivo, indomable, de la medicina, con pánico a las amenazas de su salud. Supone una escalada fantástica del consumo médico que desafía completamente los objetivos y finalidades de la medicina, además del presupuesto farmacéutico y la atención de urgencias.

- Consumo de amor rápido, alejado de sentimientos y auténtico erotismo; consumo de amor aséptico y virtual a través de chats y ciberidilios. 
- Consumo de información sin límites, sin posibilidad de ser transformada en conocimiento a través de la reflexión, ya que los medios deben ser más rápidos que los contenidos.

- El consumo de drogas se ha vuelto un verdadero problema, ya que es el emergente más doloroso y brutal del estilo de vida posmoderno. Lo peor es la trivialización del consumo, que ha llevado a considerarlo algo "normal" en una amplia franja de edad.

- Consumo de todo tipo de místicas: secularizada la religión del progreso, vuelve a abrirse el espacio de lo genuinamente místico. Lo místico ya no tiene por referencia a Dios, la ciencia, la patria o la clase obrera. Lo místico hoy es el presente.

Ocurre que el viejo relato único de la Modernidad se ha quebrado en mil minúsculos relatos. Estoy de acuerdo con Salvador Paniker (Paniker, 2000) en su idea de que cada cual ha de inventar su propia leyenda, inventar su propia mística. Pero dotarse de una mística particular se hace muy complicado cuando no existen valores absolutos de referencia.

Se corre entonces el riesgo de la afiliación a la mística más preponderante, la mística del consumo, de objetos y de sustancias, del trabajo sin pausa y a veces sin razón, la mística de la agenda, la cartera llena y, quizás, la vida vacía.

Las soluciones que la medicina ofrece a este reto son las propias del momento, soluciones rápidas: tecnológicas y químicas. Son eficaces pero parciales, incompletas, poco duraderas y con efectos secundarios.

En lugar de "aclarar" al sujeto, de "señalarle" la necesidad de una vida íntima, más importante que la privada y la pública para poder cultivar esa mística individual aclaratoria, la medicina opta (y el sujeto elige mayoritariamente) por el adormecimiento o la exaltación química, por la enajenación en vez del ensimismamiento.

No es de extrañar, el cultivo de la vida íntima requiere como elementos imprescindibles el silencio y la reflexión, algo de cultivo ecológico para una gran mayoría de nuestra sociedad.

Para el yoga, sin silencio no hay aliento; sin aliento no hay vida. Para la meditación tántrica, el silencio es la propia identidad, porque solo en el silencio se puede ser. Para Pascal, la receta para la salud mental del hombre estaba en su capacidad de permanecer media hora diaria solo y en silencio.

\section{EL RIESGO COMO FACTOR DE LA VIDA}

Nuestra época ya no es la que describe Stefan Zweig en sus memorias (Zweig, 2002), ya no hay seguridades previas.

La carencia de cobijo bajo grandes ideales y metarrelatos (Dios, patria, ideologías), a la par que la globalización que hace que todo influya sobre todos, deriva en una necesidad de prevención en todos los ámbitos de la vida que hipertrofia la angustia, generando un repunte de todos los cuadros clínicos asociados a ella, e incluso la aparición de algunos nuevos como lo que Fernández Blanco denomina como el síndrome de stress pre-traumático (2004) y que aparece como angustia anticipatoria ante acontecimientos sociales como los atentados, la amenaza de nuevas infecciones, el sufrir todo tipo de patologías o el no llegar a tener hijos sanos.

El terror que salpica desde dentro y fuera de los medios de comunicación lleva la experiencia extrema a la vida cotidiana; salir de casa se convierte para muchos en toda una aventura plagada de amenazas. Como consecuencia, la demanda de libertad de la modernidad se ha sustituido por la demanda de seguridad posmoderna.

Con todo lo extrema que parece la vida, nunca antes se ha temido más a la muerte, la vejez o la invalidez que en los últimos tiempos. Esta negación de la edad y de la muerte es otra manifestación del desprendimiento de la temporalidad y de la desrrealización: la vida como objeto de ficción, justo ahora cuando la vida no pertenece a Dios, no pertenece a la patria, no pertenece a la revolución, sino que nos pertenece a cada uno.

El hombre de hoy ya no puede apelar al destino, a Dios ni al azar para explicar sus temores, él es el único responsable de su cuidado, lo que le lleva a la angustia permanente de la prevención (colesterol, mamografías, revisiones periódicas, amniocentesis, consejo genético...). Todo debe ser prevenido. No es de extrañar el repunte de los cuadros fóbicos, en especial la hipocondría y los llamados trastornos somatoformes experimentado en los últimos años.

\section{DEVALUACIÓN DEL PENSAMIENTO Y PRIMACÍA DE LA EMOCIÓN}

El peso del saber y el pensamiento como un valor fundamental ligado a la tradición y a la formación de la persona se han devaluado en beneficio de un saber instrumental y de la búsqueda de emociones como ideal predominante. 
Sin la consistencia clásica, este saber es frágil, expuesto a la controversia, lo que se traduce en una desconfianza del sujeto ante los repetidos cambios de criterio científico, en una demanda de una segunda opinión, en la proliferación de ilustrados de Internet, de derivación a otros saberes alternativos, de manuales de autoayuda y de una progresiva "rappelización" de la sociedad.

Marina (Marina, 2000) afirma que el posmodernismo nos ha contagiado el síndrome de inmunodeficiencia mental que aniquila nuestras defensas racionales haciéndonos vulnerables a cualquier idea por débil que esta sea. El remedio según Marina es estudiar y pensar más.

En medicina, el lugar del sujeto - supuesto saber imprescindible para la cura - ha sido sustituido por el del objeto - supuesto saber encarnado en la tecnología y las nuevas "máquinas" - , hecho de consecuencias devastadoras en la estructura de la relación médico-enfermo. El código ético ha sido sustituido por el código penal.

En cuanto a las emociones, si la Modernidad valoró y colocó en un lugar de privilegio a la razón como único criterio de verdad, la Posmodernidad ha optado por absolutizar los sentimientos. El "pienso, luego existo" de Descartes ha sido sustituido por el "siento, luego existo".

Las grandes concentraciones posmodernas, salvo contadas excepciones, no son motivadas por ideas o proyectos, sino por la búsqueda de sensaciones colectivas, como en el caso del botellón, el fútbol o los conciertos de rock.

Solo en un escenario así, puede proliferar un tipo de individuo permanentemente cuidadoso de su salud pero que arriesga su vida en todo tipo de deportes de riesgo y aventuras. Está hiperinformado, pero es cada vez más permeable a todo tipo de esoterismos, curanderos, adivinadores y gurús. Relajado respecto al saber y las ideologías, pero perfeccionista en el bricolaje. Alérgico al esfuerzo, las normas coercitivas y la autoridad, no deja de imponérselas a él mismo con crueles regímenes dietéticos y esfuerzos deportivos desproporcionados. Discreto y contenido frente a la muerte, consume vorazmente todo tipo de terapias "psi "en las que poder gritar, llorar, insultar y maldecir en la intimidad.

\section{CAMBIOS EN LA ESTRUCTURA FAMILIAR Y LA FUN- CIÓN DE LOS HIJOS}

El cambio en las estructuras familiares obedece a múltiples factores, como el acceso de la mujer al trabajo y el control de la natalidad, el aumento de la expectativa de vida, el alargamiento de todas las fases del ciclo vital de la familia o el número de divorcios, que en nuestro país pasó de 15.000 en 1982 a 40.000 en 2001. Pero quizás sea el proceso de transición de una sociedad rural a una postindustrial, dónde se produce una substitución de las familias por los individuos como unidades centrales en la vida social. Con ello culmina el proceso de individualización y se pasa de las estrategias colectivas a las individuales propias de la Posmodernidad.

En nuestro país, el cambio de una estructura familiar clásica de tipo compleja, nuclear, en la que convivían dos o tres generaciones, ha sido evidente a favor del aumento exponencial de hogares unifamiliares, monoparentales y reconstituidos, equiparándose cada vez más al resto de Europa Occidental, dónde son mayoría hace décadas. En Paris, por ejemplo, alrededor del $70 \%$ de los hogares son de solitarios.

En este sentido, sociólogos como Coleman (Coleman y Torsten, 1989) entienden que al cambio familiar que acompaña al proceso de modernización, se sucederán tres modelos consecutivos de familia:

1. Pre-Moderno: demanda "cantidad" de hijos en función de considerarlos "fuente de rentas" o "bienes de producción", capaces de "devolver" lo invertido en ellos y de ocuparse de los padres en su ancianidad. El caso más extendido es el de la familia campesina.

2. Moderno: tras la llegada de la revolución industrial y del consiguiente fenómeno migratorio a la ciudad, se generaliza (sobre todo en la burguesía urbana) este modelo, que ya no demanda cantidad, sino "calidad" de hijos, porque los considera "bienes de inversión". Aquí ya no se trata de explotar a los hijos, sino de invertir en ellos a fin de asegurarles un mejor y más brillante futuro.

3. Post-moderno: tras la consolidación de la sociedad de consumo y del Estado del Bienestar, aparecería, sobre todo en los nuevos profesionales urbanos, este nuevo modelo, que continuaría demandando calidad y no cantidad de hijos, pero ya considerados como meros "bienes de lujo o de consumo ostentoso".

Por otro lado, parece claro que la familia moderna dejó a un lado importantes funciones económicas y educativas para convertirse en algo parecido a una agencia dispensadora de servicios afectivos como apunta Miguel Requena (Requena, 1999).

De la carencia afectiva de los hijos en las familias premodernas, se ha pasado a la hiperprotección de los mismos en las familias posmodernas. 
Una y otra presentan sus patologías. La que nos ocupa hoy día determina unos sujetos frágiles e inseguros, que pueden llegar a dudar de su capacidad para enfrentarse a un mundo cuyos peligros, amenazas y dificultades están pronta y puntualmente resueltos por los padres. Entiendo que algo de este orden está determinando el creciente número de adolescentes que cuelgan sus estudios porque "se agobian" hasta el punto de presentar cuadros de ansiedad sintomáticos.

\section{A MODO DE EPÍLOGO}

La clínica psiquiátrica constituye un observatorio privilegiado de la realidad social. El sufrimiento psíquico plasma de forma inequívoca los malestares que acechan al ser humano en cada momento de su historia y evolución.

Lo expuesto en esta breve reflexión no es más que la constatación de unos hechos y el ensayo de alguna explicación. La conclusión lógica de estas ideas sería el apunte de alguna solución o medida capaz de mitigar los malestares diagnosticados, tarea que quizás escapa a la formación de un médico psiquiatra; no obstante intentaremos anotar algunas reflexiones al respecto.

La plasticidad del cerebro humano para resolver problemas y adaptarse al medio es extraordinaria, pero los tiempos de adaptación son también muy lentos. Los cambios descritos y operados en nuestro entorno han sido lo suficientemente rápidos como para que aún hoy, no solo no nos hayamos adaptado, sino que tampoco podamos saber a través de qué cambios estructurales de nuestro cerebro se llevarán a cabo. Cambios no solo de impacto filogenético y ontogénico a nivel individual, sino también relacional, colectivo y social.

Reza un proverbio Zen: "no se puede cambiar la trayectoria de la flecha cuando esta está en el aire". Podemos dar cuenta de los cambios pero no podemos saber hacia dónde nos llevan.

Teniendo en cuenta esta incertidumbre en la que tampoco es desdeñable la intervención del factor de azar que señala la física cuántica, sí podemos identificar algunas señales del sentido del cambio.

En lo tocante a la crisis de valores propios de la época posmoderna parece observarse un incipiente alumbramiento de nuevos valores tales como la Ecología, el laicismo integrador de diferencias, la igualdad de géneros o la justicia social entendida desde postulados menos ideológicos o políticos y más pragmáticos derivados de la actual crisis económica mundial.

La transformación de la vivencia del tiempo y la devaluación de los sentimientos de pudor y vergüenza han supuesto el cambio de lo que antes era un sufrir principalmente mediado por el pensamiento - la culpa, la vergüenza o el remordimiento- por la patología derivada del acto - trastornos impulsivos, de personalidad, de alimentación- y la ansiedad. Al igual que ocurre en la clínica individual, es posible que estemos asistiendo a una desaceleración del tiempo psíquico propia del final de las fases hipomaníacas e inicio de las normotímicas. Es función de los políticos y de todos los agentes sociales creadores de opinión, el favorecer y fomentar la vuelta a un tiempo más humano en el que los momentos de silencio, de ensimismamiento, de contacto con uno mismo y la naturaleza vayan abriéndose camino entre la actual aceleración enajenada.

Las múltiples voces que cada día más y desde todos los ámbitos reclaman una intervención decidida sobre la educación y las aulas, albergan la esperanza de la aparición de una nueva Ley que devuelva con claridad la posición jerárquica a los agentes que deben simbolizar la autoridad y aquellos a quienes tienen el deber y la necesidad de reconocerla.

Se hacen necesarios nuevos planteamientos políticos y sociales sobre la lógica del consumo que ha regido las últimas décadas. La crisis económica mundial, las diferencias y al mismo tiempo el empequeñecimiento de las distancias entre los diferentes mundos cada vez más grandes, apuntan a la necesidad de un cambio de modelos económicos y productivos mucho más globales y sostenibles.

La necesidad de libertad debe auparse sobre la actual obsesión por la seguridad y la única manera de conseguirlo es la puesta en valor de un mundo más justo y equitativo.

Finalmente, la familia humana, deberá encontrar nuevos equilibrios que favorezcan la adaptación psicológica de sus vástagos a las nuevas estructuras. Probablemente los cambios evidenciados en las estructuras familiares llevarán a un proceso de ensayo y error -como en su tiempo ocurrió con el ensayo de la convivencia en comunas- que decante aquellas fórmulas exitosas para el desarrollo humano. Muchos de los actuales modelos se demostrarán inviables y otros harán valer su oportunidad. Habrá que esperar. 
1 Las fuentes de estos datos quedan recogidas en el anexo "Datos epidemiológicos" de la bibliografía.

2 Las fuentes utilizadas para la evolución de los fármacos en la última década, fueron obtenidas del Servicio de Farmacia de la Consellería de Sanidade (2010). Xunta de Galicia.

3 Estadística de la Unidad de Hospitalización Psiquiátrica del Complejo Hospita-

\section{BIBLIOGRAFÍA}

Anderson, Perry (2000). Los Orígenes de la Posmodernidad. Barcelona: Anagrama.

Buela, A. (1997). "La Posmodernidad”. Razón Española. La Postmodernidad, no 82, pp. 211-215. http://hispavista.com/ razonespañola/re82-bue.htm

Brukner, Pascal (1996). La tentación de la inocencia. Barcelona: Anagrama.

Coleman, James y Husén, Torsten (1989). Inserción de los jóvenes en una sociedad en cambio. Madrid: Narcea.

Asociación Americana de Psiquiatría (2002). DSM IV: Manual diagnóstico y estadístico de los Trastornos Mentales. Barcelona: Masson.

Fernández Blanco, Manuel (2004). “La adolescencia hoy: adultos prematuros, niños eternos". Cuadernos de Atención Primaria, 11 (2), pp. 61-65.

Gergen, Kenneth J. (1992). El Yo saturado. Barcelona: Paidós.

Hipócrates (1987). De las aguas, los aires y los lugares. En Medicina Hipocrática, Madrid, Alianza Editorial.

Gray, John (2002). Perros de paja. Barcelona: Paidós.

Lamas Crego, Santiago (1994). Sobre el YO y otros objetos no identificados, Siso/ Saúde (Boletín da Asociación Galega de Saúde Mental), Monografía no6.

Lamas Crego, Santiago (1988). Notas para una Teoría de la Realidad, Siso/Saúde, (Boletín da Asociación Galega de Saúde Mental), Monografía no1.

Lipovetsky, Gilles (1986). La era del vacío. Barcelona: Anagrama.

Marina, J. A. (2000). Crónicas de la Ultramodernidad. Barcelona: Anagrama. lario Universitario de La Coruña. Periodo comprendido entre 1996-2005.

4 Informe Evolución de la Familia en España 2010, mayo 2010. La ruptura Familiar en España 2012. Instituto de Política Familiar (http://www.ipfe.org/documentacion.htm) (31/05/2013)

5 http://www.abc.es/20101004/comunidad-galicia/explicar-contemporaneo-20101004.html (31/05/2013)

Millon (1999). Trastornos de la Personalidad: más allá del DSM IV. Barcelona: Masson.

Paniker, Salvador (2000). Diario Amarillo. Barcelona: Areté.

Requena, M. (1999). “Pautas contemporáneas de evolución de los hogares en España". Revista internacional de Sociología $\mathrm{n}$ ㅇ 22 (tercera época), pp. 33-65.

Zweig, Stefan (2002). El Mundo de ayer: memorias de un europeo. Barcelona: Acantilado.

\section{APÉNDICE. Datos epidemiológicos}

de Almeida-Filho, N. (1987). "Social epidemiology of mental disorders. A review of Latin-American studies". Acta psychiatrica Scandinavica, 75 (1), 1-10.

Knnap, M.; Mc Daid, D.; Mossialos, E. y Thornicroft, G. (2007). Salud mental en Europa: Políticas y Prácticas. Líneas Futuras en Salud Mental. Ministerio de Sanidad y Consumo.

Ministerio de Sanidad y Consumo (2007). Estrategia en Salud Mental del Sistema Nacional de Salud.

Moffitt, T. E., Caspi, A.; Taylor, A.; Kokaua, J.; Milne, B. J.; Polanczyk, G. and Poulton, R. (2007). "How common are common mental disorders? Evidence that lifetime prevalence rates are doubled by prospective versus retrospective ascertainment". En Psychological Medicine, Cambridge: Cambridge University Press.

Newton-Howes, G.; Tyrer, P.; Anagnostakis, K.; Cooper, S.; Bowden-Jones, O.; Weaver, T. (2010). "The prevalence of personality disorder, its comorbidity with mental state disorders, and its
6 http://www.consumer.es/ web/es/educacion/universidad/2010/03/21/191878.php (31/05/2013)

7 Estas caricaturas fueron publicadas el 30 de septiembre de 2005 en el periódico danés Jyllands-Posten con el título "El rostro de Mahoma".

clinical significance in community mental health teams". Social psychiatry and psychiatric epidemiology, 45 (4), 453-60.

OMS (2007). Informe sobre la Salud en el Mundo. Salud Mental: nuevos conocimientos, nuevas esperanzas, http://www.who.int/whr/2001/es/ (31/05/2013)

Roca, M.; Gili, M.; Garcia-Garcia, M.; Salva, J.; Vives, M.; Garcia Campayo, J. et al. (2009). "Prevalence and comorbidity of common mental disorders in primary care". Journal of affective disorders, 119 (1-3), 52-8.

Serrano-Blanco, A.; Palao, D. J.; Luciano, J. V.; Pinto-Meza, A.; Lujan, L.; Fernandez, A.; et al. (2010). "Prevalence of mental disorders in primary care: results from the diagnosis and treatment of mental disorders in primary care study (DASMAP)". Social psychiatry and psychiatric epidemiology, 45 (2), 201-10.

Somers, J. M.; Goldner, E. M.; Waraich, P.; Hsu, L. (2006). "Prevalence and incidence studies of anxiety disorders: a systematic review of the literature". Canadian journal of psychiatry Revue canadienne de psychiatrie, 51 (2), 100-13.

Waraich, P; Goldner, E. M.; Somers, J. M.; Hsu, L. (2004). "Prevalence and incidence studies of mood disorders: a systematic review of the literature". Canadian journal of psychiatry Revue canadienne de psychiatrie, 49 (2), 124-38.

WHO (2000). "Cross-national comparisons of the prevalences and correlates of mental disorders, WHO International Consortium in Psychiatric Epidemiology". Bulletin of the World Health Organization, 78 (4). 